\title{
Gender Identity and Gender Performativity in Shakespeare's Selected Plays: Macbeth, Hamlet and Merry Wives of Windsor
}

\author{
Mehdi Amiri', Sara Khoshkam² \\ ${ }^{1}$ Department of Language and Literature, Islamic Azad University, E-Campus, Tehran, Iran \\ ${ }^{2} M A$ of English Language and Literature, Iran \\ Corresponding Author: Mehdi Amiri, E-mail: mehdiamiri00@gmail.com
}

\section{ARTICLE INFO} \\ Article history \\ Volume: 8 Issue: 4 \\ Funding: None \\ Key words: \\ Identity, \\ Performativity, \\ Patriarchy, \\ Femininity \\ Feminine Identity \\ Woman Role
}

Received: May 04, 2017

Accepted: July 10, 2017

Published: August 31, 2017

Advance access: August 2017

Conflicts of interest: None

\begin{abstract}
The main argument of this article is focused on three plays by William Shakespeare, Macbeth, Hamlet and Merry Wives of Windsor. There are several points in these plays which deal with woman and their rights. This article deals with Shakespeare's plays in relation to feminism, which pays more attention to the rights of women and their true identity. In all societies women are defined in terms of their relations to men as the center of power to which women have limited or no access. Judith Butler's performativity is significance on understandings of gender identity. Butler believes that gender is produced in society; also it can be changed in society. Feminism should aim to create a society in which, one's sexual anatomy is irrelevant to who one is, and what one does. Shakespeare's view of a woman is shown through his representation of female characters in his plays specifically in Macbeth, Hamlet and Merry Wives of Windsor.
\end{abstract}

\section{INTRODUCTION}

The question of identity is one of the most crucial and influential concept in the field of cultural studies. It refers mainly to deal with the greatest differences which separate people. Identity is about belonging, about what one have in common with some people and what differentiates him or her from others, and denotes a person's sense of which he or she is, based on their own assessments and responses from others. For psychologists, identity is a set of behaviors, emotions, and thought patterns that are unique to an individual. It is usually established by late adolescence or early adulthood.

The word identity is paradoxical, it means both sameness and distinctiveness, and its contradictions expand when it is applied to women. There are various types of identity which are part of man's perceived personality and perceptions; two main types of identities are self-identity and social identity. The first one which is the first step in the process of self-recognition or self-development comprises the way that we think of ourselves, whereas the second one is the identity of the group to which we feel a sense of belonging. Identity is now multi-faceted and constantly reconstructed by choice whereas individuals' identities in traditional societies were fixed and stable.
Gender is a kind of characteristics pertaining to, and differentiating between, masculinity and femininity. These characteristics may include biological sex. Some cultures have specific gender roles that can distinguish men from women. Gender is commonly used to refer to the biological sex of the animals. Gender identity refers to a personal identification with a particular gender and gender role in society. The term woman has been used with reference to the female body. There are qualitative analyses that explore and present the representations of gender; however, feminist writers challenge these dominant ideologies concerning gender roles and biological sex. One's gender is directly related to specific social roles and the expectations. Judith Butler considers the concept of being a woman to have more challenges, not only in society as a social category but also as a sense of self, or a subjective identity.

For the explanation of the ramifications of this notion it can be said that if something that is performative it produces a series of effects. Identity politics and issues of representation are based on these performances that construct what it means to be male or female, or man or woman. Shakespeare said, "All the world's a stage, and all the men and women merely players"(49). Perhaps Butler wants to assert that all 
the players perform the roles of men and women. The stakes of this claim lie in the fact that whether performed or performative, gender is socially constructed. The ability to perform gender is something that must be earned.

\section{Gender Identity: Judith Butler's Definition}

All Butler's books ask questions about the formation of identity and subjectivity. Judith Butler is a rhetoric, comparative, and poststructuralist professor who studied about gender and language. Butler believes that gender norms produce the natural sex, or a real woman, or any number of social fictions. She believes that gender is something that is not a corporeal thing but it is reproducing, changing and moving. In Butler's view, gender is only an important part of a body's identity that is presented in the world. Butler argues that:

When Beauvoir claims that 'woman' is a historical idea and not a natural fact, she clearly underscores the distinction between sex, as biological facticity, and gender, as the cultural interpretation or signification of that facticity. To be female is, according to that distinction, a facticity which has no meaning, but to be a woman is to have become a woman, to compel the body to conform to an historical idea of 'woman,' to induce the body to become a cultural sign, to materialize oneself in obedience to an historically delimited possibility, and to do this as a sustained and repeated corporeal project. (1988:522).

By claiming that gender is performative, Butler basically meant to say that one can create her or his gender by doing gendered things. Someone's behavior obeys social gender norms. This view has a lot in common with Simone de Beauvoir because she believes that one is not born as a woman, and human beings make themselves what they are through their actions in the world. Both, Butler and Beauvoir believe that gender is produced in society and that it therefore also can be changed in society.

Although biological differences are fixed, gender differences are the oppressive results of social interventions that dictate how women and men should behave. Butler argues that, "indeed, gender appears to the popular imagination as a substantial core which might well be understood as the spiritual or psychological correlate of biological sex" (ibid 528). However, since gender is social, it is thought to be mutable and alterable by political and social reform that would ultimately bring an end to women's subordination. Feminism should aim to create a society in which, one's sexual anatomy is irrelevant to who one is and what one does.

Gender Trouble (1990) is probably Butler's best-known work to date, and is widely regarded as her most important book. Sara Salih argues that:

The idea that identity is a performative construct is a complex theory that will be analyzed in detail below, but at this stage you should note that it would be incorrect to assume that, if Hegel's Spirit is a traveller (see previous chapter), Butler's subject is an actor that simply gets up and 'performs' its identity on a metaphorical stage of its own choosing. As we shall see, Butler does claim that gender identity is a sequence of acts (an idea that has ex- istential underpinnings), but she also argues that there is no pre-existing performer who does those acts, no doer behind the deed. Here she draws a distinction between performance (which presupposes the existence of a subject) and performativity (which does not). This does not mean that there is no subject, but that the subject is not exactly where we would expect to find it (45).

Gender is a process which has neither origin nor end, so that it is something that someone does. Butler departs from the common assumption that sex, gender and sexuality exist in relation to each other, so that if, for example, one is biologically female, she is expected to have feminine characteristics. Instead Butler claims that gender is unnatural, so that there is no necessary relationship between one's body and one's gender. It can be said that it is possible for someone to have a female body and not to have feminine characteristics. Butler says that:

The act that one does, the act that one performs, is, in a sense, an act that has been going on before one arrived on the scene. Hence, gender is an act which has been rehearsed, much as a script survives the particular actors who make use of it, but which requires individual actors in order to be actualized and reproduced as reality once again (1988: 526).

Actors are always already on the stage, within the terms of the performance. Just as the play requires both text and interpretation, so the body acts its part in a cultural space. Butler, as a feminist theorist writing in the1990s, argues that there is no true gender in any person; instead one's gender is performed constantly through actions and in line with various cultural conversations about ideal gender identity and sexuality. Thus, a person's gender may be in flux throughout that person's life, and it is performed constantly through both sexual actions and cultural interactions with others. Instead of imagining an essentially woman defined by the maternal body, as some feminists in the mid-twentieth century did, Butler believes that there is no essential femininity or masculinity: "There is no gender identity behind the expressions of gender; that identity is performatively constituted by the very expressions that are said to be its results" (1990: 33). In Butler's conception gender and sexuality are always produced. In her hugely popular book, Gender Trouble, she argues that norms of gender identity are constructed and stabilized within a cultural hegemony which chains gender to sex according to an imperative of heterosexual reproductive biology.

She, with conception of performativity, claims that sex is an effect of binary gender thinking rather than its origin. "All gender is a performance" (Butler, 1993:23). Femininity for her is something that is always performed and completely a social matter with identity manifested in performativity. "There is no gender identity behind the expressions of gender; that identity is per formatively constituted by the very "expressions" that are said to be its results" (ibid 25).

\section{Gender Performativity: Judith Butler's Definition}

Judith Butler's theory of performativity has an important influence on contemporary understandings of gender identity. 
Her theory of performativity makes a valuable contribution to progressive democratic politics is, however, to make a claim likely to elicit puzzled looks. Performativity is the capacity of speech and communication not simply to communicate but to act an action, or to construct an identity.

Some theorists in philosophy and gender studies, notably Judith Butler, have argued that even commonplace communication and speech acts are performative, because they define identity. In this way, performativity doesn't mean that an identity is the source of more secondary actions such as speech and gestures. Instead, it inquiries into the construction of identities as they are caused by performative actions, behaviors, and gestures.

Butler explores the relationship between power and categories of sex and gender. She argues that gender is performative: no identity exists behind the acts. Constituted through the practice of performance, the gender woman remains contingent and open to interpretation. Gender as a performative act is not a choice or a project that reflects an individual choice. Butler argues that, "Gender reality is performative which means, quite simply, that it is real only to the extent that it is performed"(1988: 527). It can be said that some kinds of acts are interpreted as expressive of a gender identity, and that these acts also conform to an expected gender identity.

The main theoretical focus will be on Judith Butler's own texts, and especially on Gender Trouble which includes both Butler's critique of feminist criticism and her ideas of gender as performance. In short, Butler views gender as something one does, rather than something one is. It can be said that what one does can creates his or her gender identity. Consequently, there is no gender identity behind the expressions of gender. Carver and Chambers argue that:

It is in these early essays, too, that the conception of performativity emerges, along with the claim that sex is an effect of binary gender thinking rather than its origin. These are again presented as radical implications of Beauvoir's existentialism. If gender is a way of existing one's body', Butler deduces, and the body is 'a field of cultural possibilities both received and reinterpreted, then both sex and gender seem to be thoroughly cultural affairs (15).

In this way, she calls for people to trouble the categories of gender through performance. Feminist theories claim that gender is the cultural interpretation of sex. Feminists found it useful to distinguish sex and gender. This enabled them to argue that many differences between women and men were socially produced and, therefore, changeable. Butler says that:

Matters have been made even worse, if not more remote, by the questions raised by the notion of gender performativity introduced in Gender Trouble.1 For if I were to argue that genders are performative, that could mean that I thought that one woke in the morning, perused the closet or some more open space for the gender of choice, donned that gender for the day, and then restored the garment to its place at night. Such a willful and instrumental subject, one who decides on its gender, is clearly not its gender from the start and fails to realize that its existence is already decided by gender(1993: x).

It can be said that the central concept of the theory is that one's gender is constructed through her own repetitive performance of gender. Butler's theory does not accept stable and coherent gender identity. Butler believes that, "gender is a repetition of norms" (ibid 95). When someone says gender is performed it means that someone has taken on a role or someone is acting in some way and that his or her acting is crucial to the gender. To say that gender is performative is a little different because for something to be performative means that it produces a series of effects. Someone acts and walks and speaks and talks in ways that consolidate an impression of being a man or being a woman.

For the explanation of the ramifications of this notion it can be said that if something that is performative it produces a series of effects. Identity politics and issues of representation are based on these performances that construct what it means to be male or female, or man or woman. Shakespeare said, "All the world's a stage, and all the men and women merely players" (YL 49). Perhaps Butler wants to assert that all the players perform the roles of men and women. The stakes of this claim lie in the fact that whether performed or performative, gender is socially constructed. The ability to perform gender is something that must be earned.

Butler argues against this system of categorizing people, stating that gender should be seen as a fluid human trait that can shift and change in a given context rather than one that remains fixed. Further, she contends that women have been grouped together based on shared characteristics and interests, which can limit their ability to choose their own identities. Butler also challenged the prevailing attitude that sex causes gender, which then defines sexuality and desire. She argued that these factors should be independent of one another rather than inextricably connected.

\section{RESULTS AND DISCUSSION}

Femininities and masculinities depict gender identities. It alludes to how much people see themselves either as male or female or being a man or woman in the public eye. Gentility and manliness are established in the social as opposed to the biological (one's sex). Individuals in the general public choose what being male or female means for instance human attributes, for example, to be prevailing, inactive, strong, overcome, shy, or enthusiastic. These qualities are joined with gender parts. Prevailing, forceful, overcome are connected with male or masculine identity while to be inactive, bashful and passionate as female or womanlike identity.

According to Hoftstede:

Masculinity stands for a society in which social gender roles are clearly distinct: Men are supposed to be assertive, tough, and focused on material success; women are supposed to be more modest, tender, and concerned with the quality of life. [...]. Femininity stands for a society in which social gender roles overlap: Both men and women are supposed to be modest, tender, and concerned with the quality of life. (297-8)

In western culture, characteristically, men are forceful, aggressive and instrumentally oriented while women are un- 
involved, helpful and expressive. Early deduction frequently accepted that this division depended on hidden intrinsic contrasts in qualities, attributes and demeanors of guys and females. In this more established setting, measures of femininity/masculinity were frequently used to analyze what were comprehended as issues of essential gender identification, for instance, feminine guys or masculine females.

The plays of Shakespeare were composed to be performed by men, just men. The predominant tradition of Shakespeare's drama requested that not a single women were to be seen in front of an audience as performing artists. Sometimes male performing artists played women parts. This was not a new tradition, however the theaters in which it was utilized were new, and the other traditions utilized as a part of the new structures were being designed by Shakespeare and his kindred on-screen characters. The tradition of just men being on-screen characters was one which had directed the portrayal of humans in front of an audience all through the reported history of English execution.

Shakespeare did not cross-cast his plays. He worked inside the main tradition accessible to him. To be sure the very idea of gender, as we comprehend it today, would have made no difference to him. The association of gender to natural sex and to sexuality is a current late twentieth century idea. For Shakespeare, a gender was from its Latin root genus, a sort. The word's guideline implications would have been syntactic.

\section{Role of Gender and Sex in Macbeth}

Most likely none of Shakespeare's plays is so expressing in outlining male characters from female characters as is $\mathrm{Mac}$ beth $(M C)$. Male, counting the plural and such evident, subordinates as masculine, masculinity, and unmanned seems more than 40 times, quite often with a cognizant feeling of characterizing the term, or rather, of characterizing a man by the term. Female, counting comparative developments, shows up about a third as often, with a comparable feeling of exact definition. What presents itself in this play is a conflation of sex parts and of gender, and a showing that human creatures are by nature sexual creatures. Whenever men and women venture outside these sex and gender parts, they lose their humanity. Their freedom from definition crushes them; incomprehensibly, actually, it limits them.After their great crime, Macbeth feels "cabin'd, cribb'd, confin'd, bound in/ To saucy doubts and fears" (MC 3.4.23-24), and Lady Macbeth is captive within her own sickness.

Strangely, however, Macbeth is apparently worried about regicide and authority, with the destiny of a kingdom, the play continues on the estimations of a household catastrophe. Though the history plays and the Roman plays establish their open esteems in broad daylight spaces, a few of the tragedies, this one especially, seem to happen inside and to concentrate on the qualities that are characterized by and encapsulated in individual and familial connections. Positively, the play starts on the fight zone where the trustworthiness of the country is raised doubt about, and it ends there additionally, regardless of the possibility that the last scene is arranged in Macbeth's château. However, the scenes we recollect most, those in the immense center of the play, are indoor scenes, dependent upon the relationship of a couple, of man and lady.Similarly, the main appearance of spouse is Lady Macbeth's on edge severing from "Had he not resembled/My father as he slept, I haddone't" to greet "My husband!" (MC2.2.13).

As Macbeth's wife, Lady Macbeth is seen and judged by the parts and capacities that a legitimate wife satisfies and performs. Given her station, there are two: to give beneficiaries to her master, and to be his leader. It is in the last capacity that Duncan sees her as he lands at Inverness:"See, see, our honor'd hostess!" (MC 1.6.10). Most likely it is no mishap that Duncan's shout finishes a discourse of Banquo's that suggests the tyke bearing part:

This guest of summer, The temple-haunting marlet, does approve, By his lov'dmansionry, that the heaven's breath Smell wooingly here; no jutty, frieze, Buttress, nor coign of vantage, but this bird Hath made his pendant bed and procrant cradle. Where they most breed and haunt, I have observ'dThe air is delicate. (MC 3.10)

Not an especially appealing scene in execution since such a large amount of it is overwhelmed by Macduff's "witty" tyke playing straight-man to his mom, this scene more than whatever other focuses on the familial connections and the disturbance of these bonds and connections. A similarly troublesome scene, both in reading and execution, quickly tails; it is a practically actionless scene liable to exhaust both a reader and an observer, but then it unites every one of the qualities and worries of the play. The scene partitions into two parts, Malcolm's trying of Macduff's reliability, and Macduff's reactions (and responses) after being educated of the butcher of his family. These beautiful beats are isolated by lines worried about the lord's shrewd.

In spite of the fact that the play has a place with the Macbeths, the attestation of the more full and more mind boggling estimations of peace and family and humankind are expressed and sensationalized most emphatically in the Macduffs, regardless of Lady Macduff's objection that in abandoning her and their kids Macduffs"wants the natural touch" (MC4.2.9). Macduff's ability to see as normal to man the ownership and even the demeanor of feeling places a wealthier meaning of man than only that of a male fit for determined bravery in fight and notwithstanding passing. This definition counters that suggested by the First Murderer, are men, my liege" (MC3.1.90). Lady Macduff's intuitive depend on the procrant winged animals in her urgent situation:

He poor wren,

The most diminutive of birds,

Will fight, her young ones in her nest (MC4.2.9-11)

This implies the desolate and unnatural Lady Macbeth whose manor bears the outward indications of a wonderful seat in giving well being to the marlet yet no assurance for mankind: to be sure harbors no humankind. So, the standard against which Macbeth works is a customary meaning of man as valorous, firm, telling, accommodating, and restricted; and a conventional meaning of lady as delicate, maternal, feeding, an assistance meet to her better half, others conscious, and constrained. The best possible man and the correct lady are both wealthier than the oversimplified gen- 
eralization even in the genuinely confined universe of this play; however basic to full mankind is constraint inside that characterized part.

\section{Female Loneliness in Hamlet}

While the female characters in the comedies are introduced as securing and tending each other and frequently the group everywhere through their partnerships with other women, in the tragedies we are given the after effect of both misalliance and seclusion. This part will look at the idea of the organizations together shaped by the two female characters in Hamlet, Gertrude and Ophelia, and how these collusions influence the activity of the play.

In the beginning scenes of Hamlet, Gertrude is introduced as having picked a cooperation with Claudius that deadens both her mother/child relationship and her organizations together with other women. As the play unfurls, we see Gertrude moving far from her bond with Claudius and recovering her part as a mother to Hamlet. She is, be that as it may, unfit to interface with Ophelia until her death, when she grieves her misfortune. Current mental hypothesis can reveal some insight into the Gertrude introduced in the initial couple of demonstrations of the play. In her great work "In a Different Voice: Psychological Theory and Women's Development", Carol Gilligan talks about moral difficulties and good advancement contrasts in men and women. She states that for men, the essential concern is equity, and for women, the essential concern is mind. At the point when women depict themselves, it is basically through relationship; when men portray themselves, it is fundamentally through division and individual achievement. Men take care of business; women hold the gathering together. Obviously she presents that these are cultural examples, redundant descriptors. An intriguing issue emerges, she says, when women expect that being worried about necessities of others will hinder acknowledgment of self Yet, Gilligan contends for generally women, "The truths of relationship, however, return in the rediscovery of connection, in the realization that self and other are interdependent and that life, however valuable in itself, can only be sustained by care in relationships" (Gilligan 127).

On the stage Ophelia's franticness has been displayed as the consequence of her oppressive father, Hamlet's pitilessness, or her own particular innate madness. Bloggers on the "Talking to William Shakespeare" website suggest that:

Ophelia's madness is simply the sane response to an insane world in which her father and brother in him speak harshly, ignore her, and then leave her. Elaine Showalter argues that these stage presentations are, in fact, cultural readings, and that Ophelia's madness is seen through the lens of the culture to which the play is presented. (91)

A persuading contention is made in the RSC's latest creation by performing artist Meg Fraser, who plays Ophelia, and says that Ophelia goes distraught in light of the fact that in her sadness and quiet she is absolutely alone: Ophelia's frantic scenes sound good to me. Her frenzy is a zenith of things. Ophelia's very tranquil, unfit to convey; she's needed to smother her contemplations and emotions. Be that as it may, regardless of how seriously her father treated her, she enjoyed him. He was just about all she had — there is no mum and Laertes has gone off to France. She's genuinely keen yet it's not an extremely fortifying condition. She has no female organization. A repeating topic, at that point, for Ophelia is the loss of those whom she cherishes. Her brother to whom she shows up very associated leaves ahead of schedule in the play encouraging her to avoid Hamlet.

Since Ophelia appears to have no other associations with individuals, her father being fixated on the maintenance of Claudius' energy and the following of Hamlet's franticness, Ophelia is distant from everyone else. She has neither female partnership nor female friend; she doesn't have anybody she can tend. From the point of view of Taylor's hypothesis, Ophelia alone is damned. Ophelia's first passage is with Laertes. It is evident at the highest point of the scene that the connection amongst Ophelia and Laertes is a nearby one. Laertes requests that Ophelia think of him before she even goes to rest that night. Ophelia joyfully concurs, yet then he suddenly changes course and without bothering to smooth the unpleasant edges of his notice, he discloses to Ophelia that Hamlet just pretends to love her, and that he truly does not love her. As the group of onlookers, we are not aware of the data that leads Laertes to this declaration. The activity, in any case, is in Ophelia's reaction. The words take her back, actually in a few preparations of the play. Helena Bohnam Carter's Ophelia.

\section{The Role of Woman and Female identity in The Merry Wives of Windsor}

The Merry Wives of Windsor is a comic drama by William Shakespeare. Likely written in 1597-8, Merry Wives is Shakespeare's most white collar class play in setting, topic, and viewpoint. It's likewise one of his most absurd works, utilizing physical stiflers and linguistic jokes to build up a comic tone that impact the play's definitive soul of compromise, after every one of the interests have been dealt with.

Merry Wives gives an impression of life in an English commonplace town as it was inhabited the season of the play's first execution. It alludes to other, more seasoned plays; the principle plot nearly takes after all Pecorone, a 1558 Italian play by Ser Giovanni Fiorentino. This plot and the essential subplot additionally draw on old Roman comic drama and medieval joke. In spite of the fact that the play contains characters both above and underneath the working class, and also culturally stereotyped nonnatives, eventually everything capacities to show the absorbing energy of the white collar class.

In this play, the characters Mistress Ford and Mistress Page look for exact retribution on the lush Falstaff for his fizzled endeavor to charm them for delight and financial pick up. Interwoven with this plot is the opposition of the three suitors Slender, Doctor Caius and Fenton, who all look for the hand of youthful Anne Page. Both plots happened as expected in Act 5 as a pixie play is assembled in the backwoods for the aims of mortifying Falstaff before the town and for Anne to abscond with one of the two suitors supported by her folks. At last, Mistress Ford and Mistress Page, alongside other townsfolk, prevail with regards to disgracing Falstaff, 
while Anne Page, against her parent's desires, weds the man of her picking, Fenton.

Mistress Ford and Mistress Page have a fraternity that makes a sheltered situation enabling both women to voice their sentiments and musings transparently with each other. Through seeing their private discussions in a few scenes, the crowd gets a handle on a superior comprehension of both their characters as these spouses feel good venturing far from their cliché wifely auras and actually move into solid complex people. Carole Mckewin calls this private space women share a"counter universe" where "they provide space which women together can express their own perceptions and identities, comment on masculine society, and gather strength and engage in reconnaissance to act in it" (McKewin 118-119).

She additionally clarifies that scenes in Shakespeare plays where the lady hold these private discussions "reveals the freedoms and constraints of women in the patriarchal society of Shakespeare plays" (ibid). Basically this space gives Mistress Ford and Mistress Page in The Merry Wives of Windsor a chance to convey what needs be without breaking the guidelines of the patriarchal society of Windsor. In concordance with McKewin's synopsis of what women discuss in these private circles, Mistress Ford and Mistress Page examine the men that encompass them, how they are distorted by others, and how to look for vindicate on Falstaff. Mistress Ford, who is twisted on vindicate, still stresses over her open picture when she illuminates Mistress Page:

Nay, 1 will consent to act any villainy against him, that may not sully the chariness of our honesty. O, that my husband saw this letter! it would give eternal food to his jealousy.

Mrs. Page. Why, look, where he comes; and my good man too: he's as far from jealousy, as I am from giving him cause; and that, I hope, is an unmeasurable distance. Mrs. Ford. You are the liappier woman. Mrs. Page. Let's consult together against this greasy knight: Come hither. (MWW 2.1. 86-87).

Mistress Ford's worries demonstrate that she needs to plot against Falstaff, as long as her identity in people in general eye as a decent and docile housewife is not traded off. Courtesan Page, who has comparative objectives, additionally needs to abstain from corrupting her picture, however the picture she maintains contrasts from Mistress Ford's.

Discourse about Anne's character made by her suitors Slender and Dr. Caius in the play by and large concentrates on what they trust Anne speaks to as a youthful English young lady as opposed to gives knowledge into her genuine identity. Rachel Prusko underpins this claim taking note of "Her (Anne's) suitors, meanwhile, well acquainted with Anne's financial situation, seem to know little of Anne herself" (Prusko 56). The play opens up to a warmed exchange between Sir Hugh Evans, Robert Shallow, and Master Abraham Slender that rapidly moves to the theme of Slender seeking after Anne Page as a spouse. Evans depicts Anne as "pretty virginity" and Shallow affirms that "she has good gifts" when trying to persuade Slender to pursue Anne. ( $M W W 1.1 .39,51)$. They additionally educate Slender that Anne Page has a tremendous endowment since her family is exceptionally well off; such a settlement would add to his own particular riches.
These men basically regard Anne Page as a prize to be won: a prize yet that is exceptionally delightful and worth an incredible arrangement. Dr. Caius too considers Anne Page as a trophy spouse when he advises Mistress Quickly“I will have myself Anne Page" ( $M W W$ 1.4.104).

Dr. Caius alludes to Anne Page as a question instead of a man. Slender and Dr. Caius' perspectives towards wedding Anne and Anne's dissatisfaction with both men originates from pre-wedding assurance traditions of the Renaissance time. Mary Beth Rose maps out the contrasts between the privileges of women as per the laws written in Renaissance England and more up to date grant that undermines these laws. She states "In the realm of the legal, we can observe that a married woman in Renaissance England forfeited both agency and identity" (Rose 293).As Rose notes, in any case, this thought has been disproved by numerous scholars who have delivered "abundant empirical evidence to demonstrate that women exercised legal agency on a broad scale that contradicted their conceptual legal status, buying, selling, and bequeathing property and actively negotiating the marriages of their children" (ibid). Juliet Dusinberre's exploration achieved an indistinguishable accord from she states"Elizabethan wives enjoyed a working equality with their husbands which made foreigners declare them to be more liberated in practice than women in any other country" (Dusinberre 127). Both Slender and Dr. Caius' perspectives encapsulate the thoughts put forward in the real laws that Anne Page would be their property after marriage. She basically turns into a way to more riches and influence for both men as opposed to a friend.

Anne's whirlwind sentiment with Fenton develops into the most reasonable, good relationship in the play as both show commitment and friendship towards each other, and both acknowledge entirely and appreciate the other's identity. Jennifer Higginbotham noticed that"Rather than emphasizing Anne's identity as their (Master and Mistress Page's) child, the play largely presents her (Anne) in relation to Fenton as a romantic heroine" (Higginbotham 115).

Mistress Page and Mistress Ford additionally challenge specialist inside the controls of their relational unions exemplifying thoughts put forward by Puritan secularism, for example,"offering women an identity apart from their husbands, which made it possible for them to challenge their husband's authority" (Dusinberre 88). Mistress Page moves her significant other's power by plotting against him in the last scene masterminding their girl Anne to wed Dr. Caius rather than Master Page's favored suitor Slender. Mistress Ford, mindful of her better half's envy, misleads and embarrass Master Ford before his friends demonstrating that he can't control her activities or conduct. Contrasted with other witty women in Shakespeare plays, these three spouses all the more transparently contradict male specialist by making a move against it instead of just verbally restricting it. You might need to make this para two. It is dreadfully long.

Special lady Ford, similar to Anne Page, plots to embarrass others so as to maintain a strategic distance from an undesirable destiny. Disgracefully sought after by Falstaff and blamed for infidelity by her better half, Mistress Ford cravings to maintain her modest picture in Windsor and chooses to embarrass both Falstaff and Master Ford with a specif- 
ic end goal to draw consideration far from the allegations. Dusinberrre examine the significance ofchastity to women stating, "In the ethics of courtly love, honor is to a man as chastity is to a woman, a condition of life essential to his self-respect and his sense of identity as an individual, but intangible, and dependent not so much on innate virtue as on the reputation for virtue among the men" (33).

\section{CONCLUSION}

One of the diligent themes of enthusiasm for the field of Shakespeare's dramas ponders is what considers the different parts that women play in the troubadour's comedies and tragedies. Artistic and authentic researchers attest that women did not appreciate political, monetary, or social equality with men amid Shakespeare's chance and this verifiable the truth is critical to remember while examining the assortment of female characters in the plays of Shakespeare. In this Shakespearean culture, it was men who held only the official posts of specialist and power, and men who had the organization and impact to coordinate the result of occasions.

Many of Shakespeare's plays consider woman and consider them in alower place than men. As an example this essay referred to Ophelia who was seen as a mad woman. She felt a great loneliness since she was treated as a mad lady. On the other hand this play referred to the play of Merry Wives. Here in this play one can see different woman having different identities. Their loneliness and same feeling made them to have a bond made of females. The first paly which was discussed in this paper was Macbeth in which the researcher studied the role and identity of woman based on theories of Butler.

\section{REFERENCES}

Butler, Judith. "Performative Acts and Gender Constitution: An Essay in Phenomenology and Feminist Theory".
Theatre Journal. Johns Hopkins University Press, 1988. Butler, Judith. Bodies that Matter. New York: Routledge, 1993.

Carver, Terrell and Samuel A. Chambers. Judith Butler's Precarious Politics: Critical Encounters. New York: Routledge, 2008.

Dusinberre, Juliet. Shakespeare and the Nature of Women. 2nd ed. NY: St. Martin's, 1996. Print.

Gilligan, C. In a \& Arent voice. Cambridge, MA: Harvard University Press, 1982.

Higginbotham, Jennifer. "Teaching children their behaviors in The Merry Wives of Windsor." Gajowski and Rackin, 109-120.

Hofstede, G. Culture's Consequences: International Differences in Work-Related Values. Beverly Hills, CA: Sage, 1980.

McKewin, Carole. "Counsels of Gall and Grace: Intimate Conversations between Women in Shakespeare's Plays." Greene, Lenz, and Neely 117-13.

Prusko, Rachel. "'Who hath got the right Anne?': Gossip, resistance, and Anne Page in Shakespeare's Merry Wives." Gajowski and Rackin 51-60.

Rose, Mary Beth. "Where are the Mothers in Shakespeare? Options for Gender Representation in the English Renaissance." Shakespeare Quarterly 42.3 (1991): 291314. Web. 19 April 2016.

Salih, Sara. Judith Butler. London and New York: Routledge, 2002.

Shakespeare, William. As you Like it. USA: ICON Group International, Inc, 2005.

-----. "The Merry Wives of Windsor." The Norton Shakespeare. 2nd ed. Ed. Greenblatt, Cohen, Howard, Maus. New York: W. W. Norton and Company, 2008. Print.

-----. "Macbeth." The Norton Shakespeare. 2nd ed. Ed. Greenblatt, Cohen, Howard, Maus. New York: W. W. Norton and Company, 2008. Print. 